\title{
Decent Work and Gender Discrimination in Employment of College Students
}

\author{
Yu Liu ${ }^{1, a}$, Zhaoqi Peng ${ }^{2, b,{ }^{*}}$ \\ ${ }^{1}$ School of Economics and Management, Beijing Jiaotong University, Beijing China \\ ${ }^{2}$ School of Economics and Management, Beijing Jiaotong University, Beijing China \\ a627785620@qq.com, b zhqpeng@bjtu.edu.cn \\ * Yu Liu
}

Keywords: decent work; gender discrimination in employment; college students

\begin{abstract}
The new concept of "decent work" was first proposed by the new director of the ILO Somalia in 1999, and has been the concern of all countries. Decent work advocates the elimination of female employment discrimination and the elimination of female employment discrimination can promote the realization of decent work. With the increase of graduates in our country, the employment discrimination of female college students is becoming more and more serious. It is necessary for the government, society, enterprise and female college students to work together to solve the problem of gender discrimination in employment.
\end{abstract}

\section{Introduction}

In 1958, the International Labor Organization adopted the Discrimination (Employment and Occupation) Convention, and it pointed out that distinction, exclusion or preference based on sex of gender discrimination in employment is, the consequences are the employment opportunity equal or equal treatment is cancelled or damaged, but one case that the requirement of work is special should not be regarded as discrimination. College Students' employment gender discrimination refers to all aspects of the employing units in the recruitment of college graduates, in addition to hinder the normal production or job is not suitable for female college students jobs according to law, companies refuse to hire female students or improve on female college students' employment standard by gender, leads to equality of female college students career opportunities is damaged by an overt or covert means.

In June 1999, the new director of the ILO Somalia first proposed the new concept of "decent work" in the eighty-seventh session of the International Labor conference, it is "in freedom and equality, security and dignity of the security conditions, both men and women are able to get decent and productive work." In order to ensure the implementation of the strategic goal of decent work, the government must promote "the promotion of the rights", "employment" and "social protection" and "social dialogue" four goals, to ensure that the majority of workers could work under the conditions of freedom, justice, security and dignity[1].

Decent labor advocate the elimination of employment discrimination, both men and women enjoy the equal rights with obtain remuneration, rest, vacation, occupation training and education rights. They also enjoy the protection of safety and health in professional work, the right to social insurance and welfare, and the freedom of association and collective bargaining power. The ILO believes that gender equality is the key factor to promote the reform of the social system, which is consistent with the four basic strategic goals of decent labor.

\section{The Status Quo of College Students' Gender Discrimination}

2.1 Employment access conditions. Gender discrimination is the most direct and obvious damage to the employment of female college students, even in government agencies and institutions. Taking into account the evasion of legal risk, there are more hidden gender discrimination in the actual 
recruitment process. The employer does not expressly set the post sex, but in the actual operation of the employer recruitment, gender is a very important part of the evaluation. In recent years, this kind of recessive gender discrimination in employment presents a serious trend.

Gender discrimination also includes physical discrimination. Compared with male college students, female college students are more likely to be discriminated against by physical factors. There is also a problem that cannot be ignored is that we can often see that in the domestic recruitment process, for female college students, employers tend to add some additional privacy issues, such as whether there is a boyfriend, when to have a children and so on[2]. Although the Labor Law clearly stipulates that women should get the basic reproductive rights, marriage rights, etc. In practice, the employer will compel them to sign additional terms not married or have children in a few years, even after the female college students pass through the interview.

2.2 Occupation Distribution. In the traditional concept and experience, the majority of women should be engaged in jobs of low technology, low income, low social status, in fact, this is also true in the distribution of "female occupation" in china. Although China's female labor force participation rate is significantly higher than that of other countries with the same level of development, but the distribution of employment of women in China is still narrow.

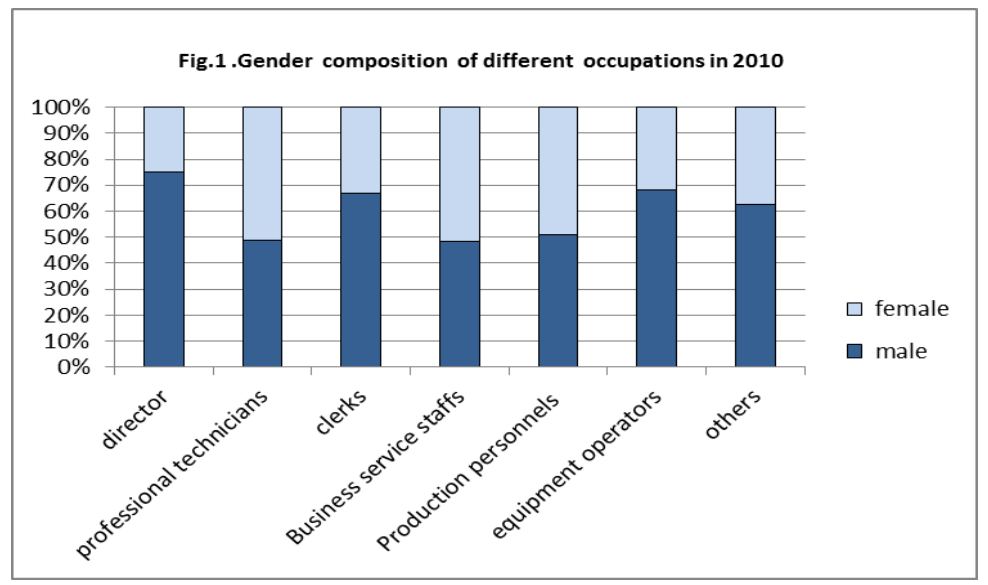

According to the sixth census data in China, in 2010, 53.2\% of the women in China concentrated in the agriculture, forestry, animal husbandry, fishing and water industry. Followed by manufacturing, to absorb $16.6 \%$ of women; wholesale and retail ranked third, to absorb $11.0 \%$ of women. The proportion of women in the above 3 sectors of employment as high as $80.8 \%$, the proportion of women employed in the other 17 industries accounted for only a total of about $19.2 \%$, the industry distribution of female employment has a high degree of concentration. Female college students who have been highly educated and have a professional expertise, in the process of employment, suffer some kind of explicit or dark employment discrimination, this sex discrimination isolate them in the so-called traditional "male industry" outside, which is a great waste of social resources. It also hinders the realization of women's self-value.

2.3 Unequal Pay for Equal Work Between Men and Women. China's labor law provides that "men and women enjoy equal pay for equal work.", but the process of women's employment in China still often encounter equal pay for non-fair treatment; female college students in the employment process also encountered such an embarrassing situation. As shown in the figure below, according to the gender pay gap report in China in 2016, there are two main categories of industries with large pay gap between men and women: male employees working in high technical positions accounted for a much higher percentage than females, including medical, professional testing, Internet, etc.; Another type of job is a serious imbalance between male and female employment because of physical factors, including construction, mining and smelting. In 2016, the average wage of women in the four industries was $30 \%$ lower than that of men, namely, medical, testing and certification, film and television media and mobile Internet. 


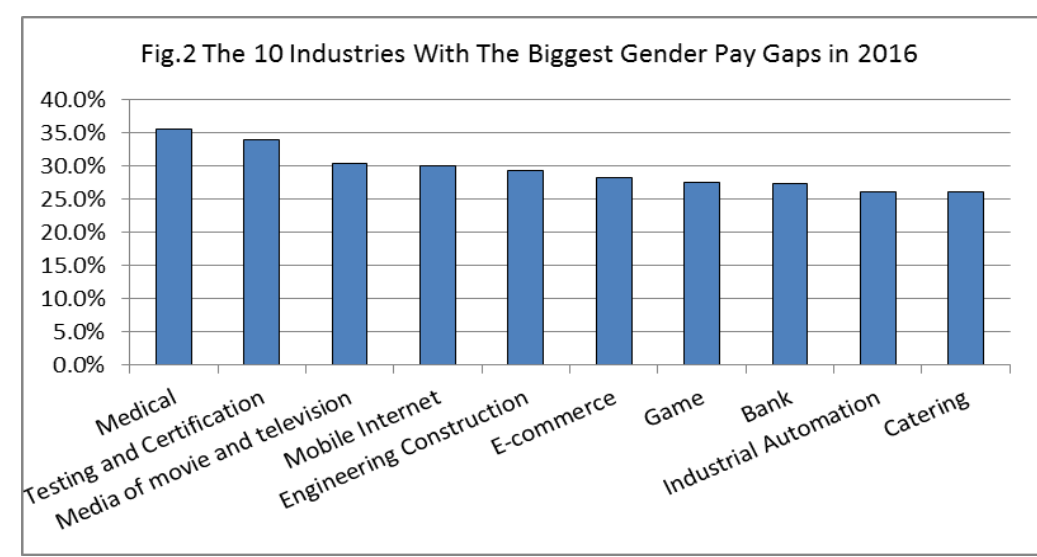

Equal pay for equal work is that men and women should pay the same remuneration for the same or similar work. However, when employers are recruiting their own employees, they are more likely to choose the men who have a high rate of return on human capital in their minds. Even if they are recruiting women, the companies are adding some conditions that men do not have. Female college students are highly educated groups, generally engaged in mental work, the labor results are usually no difference between men and women, but they have to suffer equal pay for non-fair treatment, which is disrespect for the product of female.

\section{Reasons of College Students' Gender Discrimination}

3.1 The Severe Employment Market is the Main Reason for the Employment Problem of Female College Students. Since the enrollment of colleges and universities, the number of college students in China has increased year by year, from the table we can see that the number of college students in China continued to increase rapidly, by 2016, the number of university graduates has reached 7.65 million, creating a record high. Female college students accounted for the proportion of the total number of college students increased year by year, it can be seen that the increase in the supply of female college students is an indisputable fact. However, from the demand point of view, China's sluggish consumption, shrinking exports, the impact of government policies, GDP growth is slowing. This means that the overall decline in employment demand, domestic employment needs to be reduced [3].

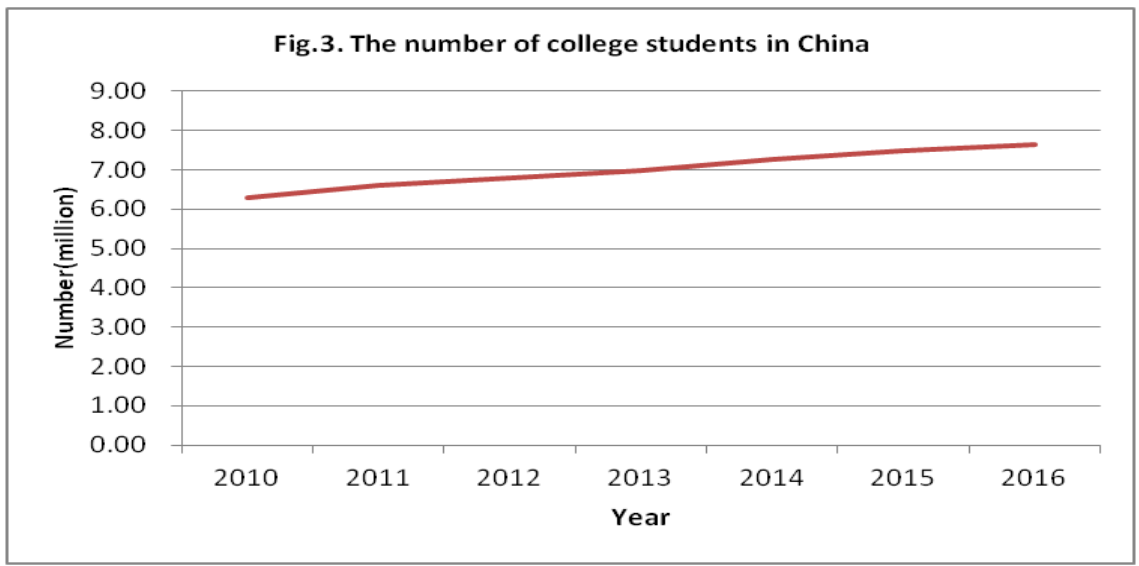

Talent supply and the demand for talent form a huge contrast, such as English, nurses, pre-school education and other professional, the proportion of female college students have been significantly higher than the proportion of male college students, the demand of the market is relatively saturated. The university graduates and employers are currently two-way choice, but the oversupply of the tense situation, the downturn in the employment situation for the employer to set a high threshold, which will bring difficulties to the employment of female college students.

3.2 The Gender Prejudice in the Traditional Cultural Concept is the Historical Reason for the Discrimination of Female College Students' Employment.

There are two main aspects of the influence of traditional ideas on female college students: 
1).Gender division of labor affects the employment of female college students. Under the traditional Chinese concept, "women stay home instead of working outside" is the most important task for Chinese women, women's social responsibility is weakened, women's family role is more concerned. women are considered to be more suitable for a number of ancillary and service industries, but not suitable for management, technical and development positions[4].

2).There is statistical discrimination against female college students. The enterprise will intentionally or unintentionally think that in the same environment, labor productivity of female college students is bound to be lower than male college students, that female college students' independence is not strong, will weak, low ability, even if some female college students are very excellent and loyalty to the enterprise, the enterprise lacks the exact personal information because of the information asymmetry, the female college students are unavoidably discriminated.

3.3 The Higher Human Capital Cost of Female College Students is the Internal Cause of Female College Students' Recessive Sex Discrimination in Employment. Enterprises believe that the return on investment for female students is lower than men.The higher human capital cost of female college students is the internal cause of female college students' recessive sex discrimination in employment. First of all, women take a long time to give birth to a child; Compared to men, women enjoy higher benefits given by national policies, but the cost of such benefits needs to be borne by the enterprise[5]. Second, during the absence of a female employee, the firm must find the right person to replace the work of the female worker, which in turn may increase the cost of the enterprise, and the business needs to pay a bonus or subsidy to the replacement worker. In short, female employees 'vacation bring the cost of wages and business risks to enterprise, so companies are more likely to choose men in the recruitment.

\section{Solving the Problems of College Students' Employment Discrimination in the Process of Decent Labor Protection}

The elimination of female employment discrimination and the promotion of decent work are complementary to each other: on the one hand, the elimination of female employment discrimination is one of the important contents to promote decent labor; on the other hand, Only in the process of promoting decent labor, women's employment discrimination can be gradually eliminated. How to combine the two is an important issue we face.

\subsection{Strengthen Legislation and Supervision to Ensure Equal Employment for Female College Students.}

1). The government should improve the legislation of employment and anti-discrimination in our country, and impose compulsory protection on the fairness of women in employment.

2). The government should also vigorously encourage employers to recruit women, and to give the corresponding preferential policies. The government should increase the punishment for acts of discrimination by employers, make employers realize that the employment discrimination behavior occurrence cost is much higher than discrimination itself, so as to reduce the discrimination to female employers.

4.2 Change the Concept of Gender Discrimination. In order to eliminate gender discrimination China ingrained feudal traditional thought, only with the cooperation of all areas of society can be implemented, it needs the support of media publicity of the idea of gender equality, to establish the consciousness of gender equality in the whole society. It can also promote the positive image of successful women and increase social recognition of women's labor value. [6].

The whole society should recognize and understand the contribution of women's fertility. Enterprises should also give respect to the contribution of female fertility, rather than discrimination. Employers can not only consider the economic interests of their own enterprises but also consider the overall social interests, they should take the initiative to bear the corresponding social responsibility and obligations [7].

4.3 Universities should Provide TArgeted Employment Guidance for Girls. For example, colleges and universities can set up some courses on women's education and other types of courses, so that female students have an objective and clear understanding on their own strengths and 
weaknesses, in order to avoid weaknesses. Many universities still stay in the lectures about employment policy, analysis of employment forms and other surface work, let alone targeted employment guidance.

4.4 Female College Students should Actively Adjust Their Attitude, Change the Concept of Employment, and Actively Adapt to the Needs of the Job Market. Influenced by traditional ideas, combined with their poor psychological quality, a lot of female college students hope to find a stable and well paid job. With the increasing the number of college graduates in our country, the competition in the job market becoming increasingly fierce. If they want to seek more job opportunities, they must abandon the inherent ideology, positively and bravely face the competition, meet the challenge. And contemporary female college students with higher education have certain professional knowledge, quality and ability. Female college students can make use of their own advantages and all available resources, take the path of independent entrepreneurship, broaden the channels of employment.

\section{References}

[1] Somavia J, "Report of Director-General : Decent work. In : 87th session of International Labor Conference", Geneva, pp.1-2, 1999.

[2] Li Wang, "Employment Discrimination of Female College Students", Journal of Jilin Business and Technology College, vol.28, no.2, pp.82-84, March 2012.

[3] Juan Huang, "Legal Thinking on Equal Employment of Men and Women", Theory Journal, vol.4, no.4, pp.92-93, 2006.

[4] Xiaoping Liu, "Gender Discrimination in The Employment Process of Female College Students", Shi Ji Qiao, no.23, pp.96-97, 2011.

[5] Jiajia Zhang, "Gender Discrimination Cannot be An Excuse for Employment Discrimination", Modern enterprise Culture, no.14, pp.40-41, 2008.

[6] Yadong Hui, "The Reasons and Countermeasures of Female College Students' employment difficulty", Economic and Social Development, vol.9, no.6, pp.125-127, April 2011.

[7] Lifeng Dai, "Female Employment Disadvantage from The Perspective of Decent Work", Economic Research Guide, vol.2, no.76, pp.59-60, 2010.

[8] Ying Shi, "Sex Discrimination And Household Discrimination In China 's Labor Market", Dong Yue Tribune, vol.32, no.10, pp.134-137, 2011. 